\title{
Analysis on the Influence of Soybean Target Price Policy on Farmers' Behavioral Decision-Making
}

\author{
Mingxing Liu, Shuguo Yang*, Hanwei Li \\ College of Economics \& Management, Heilongjiang Bayi Agricultural University, Daqing, China \\ Email: *rhwysg@163.com
}

How to cite this paper: Liu, M.X., Yang, S.G. and Li, H.W. (2018) Analysis on the Influence of Soybean Target Price Policy on Farmers' Behavioral Decision-Making. Modern Economy, 9, 889-896.

https://doi.org/10.4236/me.2018.95056

Received: February 8, 2018

Accepted: May 6, 2018

Published: May 9, 2018

Copyright ( 2018 by authors and Scientific Research Publishing Inc. This work is licensed under the Creative Commons Attribution International License (CC BY 4.0).

http://creativecommons.org/licenses/by/4.0/

\section{(c) (i) Open Access}

\begin{abstract}
For the target price policy of agricultural products, it is not only the guarantee of the free operation of the market price of agricultural products, but also the key for the government to play a leading role in it, and then actively arouse the enthusiasm of farmers, and promote the market risk to be continuously reduced. Farmers as the main body of the target price policy, in the view of the farmers, the policy will directly affect the enthusiasm of farmers to grow. Taking soybean crops as an example, the relevant departments found through the investigation of farmers. Because of the lack of organization, farmers' ability to regulate the market is severely restricted. Therefore, in order to ensure the future of soybean and other farmers in China, it has not formed a profound understanding of the price policy. In the following articles, the effective reform of crop price policy will start with the operation and mechanism of the target price policy. The problems and reasons in the implementation of the target price policy and the policy suggestions for the implementation of the target price policy are analyzed.
\end{abstract}

\section{Keywords}

Target Price, Farmer, Agricultural Subsidy Policy

\section{Introduction}

As a traditional advantage of planting crops in China, soybean has been listed as one of the experimental agricultural products in the target price policy. Although with the development of various policies in China and the continuous improvement of China's international status, as for crop soybean, it has been controlled by temporary storage, the enthusiasm of farmers to grow soybean in ${ }^{\star}$ Corresponding author. 
our country has been unable to grow on a large scale because of the low economic benefits [1]. In addition, there are also a series of problems such as the extremely high cost of soybean acquisition by some downstream enterprises, financial acquisition and so on. However, the introduction of the target price policy for soybeans has not only placed great hopes in the central department on farmers' enthusiasm for soybean planting, but also wanted to increase the enthusiasm of farmers to grow soybeans. At present, the pilot project of soybean target price policy has been carried out, but the concrete implementation effect is still to be further tested by the market.

\section{Farmers' Cognitive State and Reaction to Target Price Policy}

\subsection{Investigation Status and Basic Characteristics of Farmers}

According to the effective data investigation, the soybean planting area in our country accounted for more than $60 \%$ of the total planting area of agriculture in 2012 , but in recent years, the soybean planting area in our country is gradually declining, but on the contrary, In order to better understand the farmers' psychological views on soybean cultivation, random spot checks were conducted. Among all the farmers surveyed, the number of men was the majority. About 80 per cent of the total; of the total number of farmers surveyed, more than 60 per cent were over the age of 40; in terms of their educational level, Rural households with junior secondary education accounted for more than 50 per cent of the total; of all the farmers surveyed, 239 had the largest cultivated area and only 2 had the smallest. The average cultivated area is about 17 hectares. More than 98 percent of all farmers grow soybeans, and only two grow both soybeans and corn. Moreover, these farmers have grown soybean for a long time, among which more than $88 \%$ of them have grown soybean for more than five years. Among them, the proportion of farmers with 10 years of planting has accounted for $54 \%$ of the total. These reliable and real data suggest that farmers still have a good foundation and habits for growing soybeans. More than 97 percent of all farmers surveyed are not members of rural cooperatives. Only a small number of farmers joined the cooperative.

\subsection{Farmers' Cognition of Soybean Target Price Policy}

In recent years, there have been many pilot projects in the national soybean target price policy. In order to better understand the farmers' understanding of the target price policy, a comprehensive survey was carried out. Among them: most farmers of the soybean target price policy received information through television channels, and they were not very clear about the content of the specific policy. Among them, Farmers with little knowledge of the soybean target price policy accounted for more than $77 \%$ of the total farmers, over $11 \%$ of the total farmers, more than $4 \%$ of the farmers who knew very well, and, finally, more than $5 \%$ of the total farmers who did not understand the target price of soybeans. The 
understanding way of the policy is mainly from the television network occupying more than $65 \%$ of the total amount, and the other people know that the policy situation occupies more than $22 \%$, and the remaining small part is through the press and the like.

In the end, the majority of farmers agree with the soybean target price policy, but only a small number of farmers disagree. The above real survey data suggest that the soybean target price policy introduced in our country can meet most of the farmer's psychological needs.

Comparing the other grain subsidy policies introduced in China, in the minds of farmers, the most recognizable policy is the direct subsidy policy and the minimum purchase price policy of grain [2]. According to the survey results, in the target price policy, among the three policies of grain direct subsidy policy and minimum purchase price policy, more than $40 \%$ of the farmers think that the grain direct subsidy policy is the most important, and more than $37 \%$ of the farmers think that the minimum purchase price policy is the most important. More than $24 \%$ of the farmers think that the target price policy is the most important, while the remaining few farmers think that the temporary reserve policy is the most important. Among all the price support policies, the lowest income is the most accepted by the farmers Purchase price policy, at the same time, the risk of temporary storage policy in farmers' minds is greater. And through the above data, the most desired food policy is to reduce their risk in the market.

\subsection{Farmers' Cognitive Willingness to the Target Price Policy of Soybean}

For the time being, farmers will compare the economic benefits of growing soybeans to the economic benefits of corn, and most farmers think that the net income from growing corn is higher than that of soybeans, so they are more willing to grow corn. More than $60 \%$ of the farmers have indicated their intention to plant corn, while the remaining small number of farmers intend to continue to grow soybeans. At present, the main factor that farmers choose to plant is the price factor. There is also a small number of concerns about their own planting habits, and a very small portion of the rest to consider income or government subsidy policies; for soybean farmers, most of them are... In terms of production costs, more than $97 \%$ of farmers consider that the cost of soybean production is unreasonable, while a small number of farmers are worried about changes in policy or the increase in the means of production. It can even be said that it is on the high side. Only about $3 \%$ of the farmers think it is more reasonable. In the view of all the farmers, what they are most concerned about is the subsidy for the price of planting soybeans, among which, more than 55 percent of farmers want the state to directly subsidize the purchase price of soybeans. More than 20 percent of farmers want direct subsidies on the means of production or costs; in addition, most of them only a small number of farmers are satisfied with the price of soybeans sold in the market. The survey data show that farmers choose what kind of crops to grow. Or rational economic people who mainly pursue eco- 
nomic benefits, and they choose to grow soybeans, the main will is from the rise or fall of the expected price of soybeans.

More than $70 \%$ of the farmers think there is a positive effect, about $3 \%$ of the farmers think there is a negative impact, and the remaining part of the farmers think that there is no impact. More than 60 percent of farmers think that the target price policy for soybeans should be based on the economic benefits of corn planting. The remaining part of farmers think that their policy should be based on soybean production cost and profits in previous years, most farmers want soybean target price policy to be one year, and a small number of farmers expect three years. In the end, about one percent More than $90 \%$ of the farmers think that the target price subsidy should be distributed according to the sales volume, while the remaining small number of farmers want to pay the subsidy according to the cultivated area, that is, the subsidy you want. According to the above survey data, in the minds of all the farmers, the expectation of soybean target price policy is good, and it is also hoped that with the help of soybean target policy, farmers will be able to grow soybean more than the gain from corn planting [3].

\subsection{Farmers' Cognitive Response to Soybean Target Price Policy}

It can be seen that although most farmers do not know very well about the soybean target price policy, but with the continuous development and improvement of the policy, the implementation of the soybean target price policy has continuously released some more positive energy information to farmers, which has indirectly had a positive impact on farmers' planting decisions. According to the results of the survey, in recent years, More than $40 \%$ of the farmers did not change the soybean area, more than $30 \%$ of the farmers chose to expand the soybean planting area, only a few farmers chose to reduce the soybean planting area [4]. In recent years, the actual prices of soybean sales have been large. The price of beans is generally low.

\section{Analysis of the Problems and Causes in the Implementation of Soybean Target Price Policy}

\subsection{The Role of Policy Advocacy and Market Guidance Is Not Obvious}

It can be understood that farmers have simple access to and low awareness of the national agricultural policy. Therefore, it is necessary to strengthen policy promotion and popularization. The results of the above data survey show that. Although farmers relatively agree with the direct subsidy policy of grain, however, farmers attach more importance to the price policy that can affect the economic income of soybeans. Among them, the lowest purchase price policy, which is based on the base price, has a higher degree of approval. However, most farmers agree that there is a great risk in the temporary grain collection and storage policy, which is not a good guarantee for the farmers' income from planting. At the 
same time, it also shows that for the farmers in our country, they are the ability to resist risks is weak, and the operation of the market is not clear enough. For the number of agricultural producers in our country, the area is not only small but also the quantity is very small, so it is difficult to accurately predict the market. To sum up, it is necessary to strengthen the propaganda of the policy and give play to the guiding role of the target price policy.

\subsection{Poor Quality of Farmers and Ability of Market Regulation}

From the results of the survey, we can see that the aging of farmers is serious, and their education level is limited. Therefore, they must be slow to adjust their planting structure if they are affected by the traditional planting habits. In addition, farmers' ability to participate in market regulation is limited, and they lack the enthusiasm to participate in new modern rural cooperative organizations. On the one hand, for farmers, their market awareness is insufficient and their quality is not high. The ability to judge market information is weak. For example, if the price in the first half of the year is not high in the first half of the year of soybean planting, then most farmers choose a wait-and-see attitude. The price of half a year may be lower than that of the first half of the year; on the other hand, the farmers' degree of organization and scale is low, and they are easily affected by market risks. Therefore, the target price policy should be approved by all farmers. Its measures must pay attention to the degree of organization and marketization of the implementing objects, actively cooperate with the new agricultural production elite main body, do a good job of a series of service facilities, and promote the farmers' ability to adapt to the market to improve constantly.

\subsection{Target Price Subsidies Are Unclear}

For the soybean target price policy, its essence is a kind of agricultural support policy transferred by the central finance, in which the subsidy region and the allocation are all linked to the total soybean yield. As mentioned in the above article, in the hearts of the farmers, the most desirable form of target price subsidy is to subsidize on the basis of sales volume. The reason why there is a difference between the two forms of expected subsidy is that. In the eyes of the state and the governments at all levels, what they care about is how much soybeans farmers grow, and how much they plant will subsidize them; in the view of farmers, What they care most about is growing soybeans. How much economic gains will be generated, and how much will be paid back according to the sales price difference sold out. For the soybean target price subsidy policy, the policy content is to replenish the difference between the target price and the market price to the farmers. Although the drawbacks of the supply and circulation link in the traditional subsidy policy are well avoided, in the concrete implementation of the target price policy, different subsidy policies will inevitably bring different results. The reason why farmers have doubts about the subsidy policy, One is to 
worry about the gap between the soybean price they sell and the actual market price forecast, and the difference between them can be made up; the other is to worry about the market price forecast There is an error between the price and the target, and whether the error is true or not; the third is whether the timing of the soybean sold by oneself is appropriate, and if the price sold is below the target price, the difference can be subsidised.

\section{Policy Recommendations for the Implementation of Target Price Policy}

\subsection{Strengthen the Propaganda of Policies and Give Play to the Role of Market Orientation}

At present, although China's soybean target price policy is still in the pilot process, it indicates the policy direction of our country's price support for agricultural products. In order to promote the soybean target price policy to play a huge regulatory and guiding role, it is necessary to fully mobilize farmers' enthusiasm for planting, to enable farmers to participate fully in it, and to test the results of the policy. In order to implement the soybean target price better, we must first strengthen the propaganda of the policy. Besides the national propaganda, local governments at all levels should also carry out the promotion of the policy. In addition, they can also With the help of television media, propaganda posters, and so on, we can better explain to the farmers the specific implementation plans of the local policies and the operational objectives of the policies, and adjust their own planting structures according to the target prices and market prices. Make the target price policy play a leading role [5].

\subsection{Strengthen the Target Orientation of the Target Price Policy and Promote the Sustainable Development of Agriculture}

All farmers are most concerned about is the price and income, and the comparative income generated by the price will directly affect the enthusiasm of farmers. Therefore, for the soybean target price policy, the target price is not only the role of market supply and demand and price orientation, but also includes the adjustment of farmers' planting structure and the effect of comparative interest trend. For example, if the target price policy is driven by the target price policy, If the income from soybean cultivation is much lower than that from other crops, then farmers will choose other crops with higher returns to rotate with soybeans, which will bring about the ecological structure of agricultural production and planting. The imbalance has an impact on the sustainability of food production. Therefore, the target price policy is both price-oriented and goal-oriented, where price orientation is in line with production costs, benefits and market supply and demand. The goal orientation should give full play to its agricultural ecological energy and avoid blindly pursuing short-term economic benefits to the detriment of long-term sustainable production and development. 


\section{Conclusion}

In simple terms, although the implementation of the soybean target price policy in China will prompt the farmers grow enthusiasm to increase to a certain extent, in its essence, the soybean target price policy is to sustain the development of stable. It must be combined with other agricultural production support policies. The soybean target price policy is mainly oriented market price forming mechanism was established, and the other production policy is used to compensate for manufacturing plant selection of economic and ecological benefits of the loss. The continuous improvement of the soybean target price policy and other agricultural production support policies, the combination of its bound to prompt the enthusiasm of farmers planting soybeans, thus bring more economic and social benefits.

\section{Contributions and Limitations}

The article analyzes the farmer's perception of the soybean target price policy, willingness and reaction, found that due to the inability of farmers' quality and market regulation, policy propaganda and guide the way is not obvious, the subsidy way, reduce the enthusiasm of farmers planting soybeans and planting area decreased. On this basis, some Suggestions are put forward to improve the scientificity of soybean target price policy.

Because my research level is limited. In many aspects, this paper is still inadequate: this article is only a brief analysis of the problems existing in the implementation of soybean target price policy, and it is not comprehensive. There is a gap in the depth of the paper, and the relevant analysis and discussion are not perfect enough and need to be improved.

\section{Funding}

Undergraduate Innovation Project in China of 2015, Research on the Influence of Soybean Target Price Policy on Farmers' Behavior (No. 201510223002).

Social Science Fund Project of Heilongjiang Province, Research on the Construction of Modern Technology System of Soybean-Maize Rotation in Heilongjiang Province (No. 16JYB16).

Post-doctoral Fund Project of Government of Heilongjiang Province, Technical and Economic Analysis of Soybean-Maize Rotation in Northeast of China (No. LBH-Z15026).

Ph.D. Startup Fund Project of Heilongjiang Bayi Agricultural University, Technical and Economic Analysis of Soybean-Maize Rotation in Northeast of China (No. XDB2015-06).

\section{References}

[1] Wu, J.Y. (2016) Causes and Development Countermeasures of Soybean Area Reduction in Heihe City. Heilongjiang Agricultural Science, 7, 143-144.

[2] Zhang, Y. (2013) Effect and Prospect of Grain Direct Subsidy Policy in China. 
Agricultural Prospects, 6, 37-41.

[3] Song, X.J. and Cui, N.B. (2015) Investigation and Analysis of Cost and Income of Domestic Soybean. Heilongjiang Grain, 2, 24-26.

[4] Zhao, L.F. Analysis of Influencing Factors of Soybean Planting Area in China. Journal of Shanxi Agricultural University (Social Science Edition).

[5] Zhang, H.Q., Lu, J. and Wang, L. (2016) An Analysis of the Target Price Policy from the Perspective of Farmers' Cognition-A Case Study of Soybean Growers in Heilongjiang Province. Monthly Price Journal, 2, 22-26. 